Erschienen in: Was ist der Mensch? / Ganten, Detlev; Gerhardt, Volker; Heilinger, Jan-Christoph; Nida-Rümelin, Julian (Hrsg.). - Berlin : de Gruyter, 2008. -

(Humanprojekt ; 3). - S. 93-96. - ISBN 978-3-11-020262-5

\title{
Was ist der Mensch? Eine wahre Geschichte.
}

\section{Giovanni Galizia}

Als ich ganz klein war, wusste ich noch nichts. Ich war ja noch fast gar nicht. Die Hälfte durch noch mal die Hälfte, und wieder - ich musste immer mehr abgeben, wurde immer kleiner, und erst ganz langsim konnte ich wachsen - auch wenn ich noch lange, immer wieder, einen Teil von mir verlor.

Was heißt - verlor? Eigentlich blich ich ja bei mir, all die Hailften und Viertel und Achtel formten sich ja immer mehr um mich herum, gediehen, wurden zu Augen, zu Haut, zu Knochen - und zu Gehim. Und ich begann mich darin zu strecken - es schnneckte so gut, es roch so stark, dass ich meine Fühler aussenden musste, durch den Zellenhaufen hindurch, zu den spannenden Enden, wo es kitzelte, wo die Ströme flossen, die mich reizten, die mir Lust gaben, die mich wachsen lieben.

Ich grub mich ein, mischte mit wo ich konnte. Ich vermochte nur den inneren Gerüichen zu folgen, und doch begriff ich, was die Düfte draußen waren. Ich lebte im Dunkeln, und doch verstand ich das Licht, die Musik, die Liebe! Meine Ausläufer erfuhren von überall im Gehirn etwas, und mehr. Ich brauchte sar keine Ausläufer in den Magen zu schicken - mir war auch so immer bewusst, wann mein Körper Hunger hatte.

Mein Körper - all die vielen Zellen von denen ich mich habe trennen miissen, die ich aber alle nicht losgelassen hatte. Mein Körperdas war ich, und war ich doch nicht. Ich versuchte, ihn zu kontrollieren, oder kontrollierte er mich?

In Gehirn, da war es anders. Da war ich zuhause, da wusste ich alles. Schlieblich hatte ich alle Bereiche besucht, ich, das Bewusstseinsneuron, hatte meine Ausläufer im Sprachzentrum, im Sehzentrum, im Gefuilhlszentrum. Ich hielt nicht nur die Fäden in der Hand - ich war der Faden! Ich bin der Mensch, denn was ist er ohne mich? Was bin ich ohne mich? Wenn es kitzelte, in meinen Ausläufern, dann wusste ich: es gibt mich, ich bin da, ich lebe!

Und doch, wie sehr hatte sich alles geändert, von der Zeit als ich eine einzige Zelle war, unwissend, aber eins, zu jetzt, groß, voller 
Wissen und Sein, mit allen diesen Zellen, alle von mir abgeschnürt, und doch alle getrennt, fremd, und doch eins.

Bin ich's, oder sind sie's?

Ganz langsam dringt die Elektrode ins Gewebe ein. Ganz langsam - so wie sie es allen Patienten und ihren Angehörigen immer erzählt, wenn sie fragen: „Frau Professor, kann das denn nicht auch schief gehen?" Natülich ist das möglich. Aber sie hat schon so viele erfolgreiche Eingriffe hinter sich, sie ist dic Koryphäe auf dem Gebiet. Und mit den richtigen Vorsichtsmaßnahnten ist das Risiko kalkulierbar. Wichtig ist es, das Sprachzentrum nicht zu beschädigen. Aber selbst da ist die Informationsverarbeitung so parallel, dass ein paar zerstörte Neurone keinen bemerkbaren Schaden hinterlassen. Der Nutzen der Mikrostimulation ist demgegenüber enorm: Sie wird schon oft erfolgreich eingesetzt, bei Parkinson, bei chronischer Depression, immer mehr Zustände gibt es, bei denen wir einem schwach gewordenen Gehirnareal helfen können. Eine feine Elektrode an der richtigen Stelle, ein gut ausgewählter elektrischer Reiz, das ist ein geringerer Eingriff als ein Psychopharmakon, das das ganze Gehirn verändert.

Ganz langsam dringt sie vonwärts, durch das motorische Zentrum, durch den Assoziationskortex. Sie fragt den Patienten, was er gerade fühlt - und dieser antwortet, oder bewegt seine Finger. Zum Glück gibt es kein Schmerzempfinden im Gehirn, so dass sie ihn inmmer fragen kann, denn der Patient ist nicht betäubt. Die Mikrostimulation kann nur funktionieren, wenn sie mit der Elektrode das Ziel genau trifft. Gerade erinnert sich der Patient an seine Kindheit: Die Großmutter steht am Fenster, er rennt auf das Haus zu, durch die Wiese, die Füße werden nass - die Großnutter öffnet die Fensterflügel, und er steigt durch das Fenster in ihre Wohnung, riecht diesen besonderen Geruch, den er seitdem nie wieder so lebendig erlebt hat.

Aus dem Lautsprecher des Operationssaals hört man ein Knacken - alles, was die Elektrode anfnimmt, wird akustisch wiedergegeben. Es sind Aktionspotentiale, die Signale der einzelnen Nervenzellen, die sich wie ein eigenartiger Rhythums immer wieder neu, und doch immer wieder gleich, ergießen. Sie hat die Operation schon so oft durchgeführt, dass sie am Rhythmus des Knackens schon hören kann, wo sie ist. Pac. Papapapac. Trrrrptrptrtrk. Und gleich wird sie da sein, im Zentralganglion, im Nuclews subthalamicus. "Jetzt ganz, ganz langsam!" Tac. Takhkct. "Halt!" Das klingt eigenartig. Dieser Rhythmus wo ist sie? Sie fragt ihren Patienten. „Spiiren sie etwas?" Nein, sagt er. Es fïhlt sich aber an wie - er weiß es nicht, wie ...

Das Kitzeln war ganz anders als sonst, kalt, trocken. Kam da eine neue Zelle auf mich zu, die ich noch nicht kannte? Hatte die Blut-Hirn- 
schranke versagt? Einmal, ganz früh, waren bei einer Entzündung ganz viele Bakterien ins Gehirn gelangt, das war schon viele Jahre her, schrecklich. Ich dachte damals, das ist das Ende, überall haben sie an meinen Ästen geknabbert - aber zum Glück war das doch vorübergegangen, und ich konnte die Kontrolle wieder übernehmen. Aber dieses Gefühl werde ich nie vergessen, dieses Ausgeliefert-Sein, diese Lustlosigkeit. Ich hatte fast Lust gehabt zu sterben, nicht aus Ekel, nicht aus Schmerz - vielmehr aus Beteiligungslosigkeit. Aber jetzt, das war anders. Es knabberte nicht überall, sondern nur an einer Stelle, und das war ganz nah am Zellkörper, ganz zentral.

Sie stoppt den Vortrieb, denn die Signale sind beängstigend anders. „Hören sie mich?", sagt sie. "Ja, klar. Sind sie demn schon fertig mit der Operation?" "Nein, ich branche ihre Rückmeldung - spüren sie etwas Besonderes?" "Nein, das sagte ich ihnen doch gerade. "Sie nimmt noch ein paar Mimuten die nenronale Aktivität auf, und damn Ppapp, tac tac, prrrtsk. Stille.

Es fühlte sich an, als würde sich ein kalter Schaner über mich ergieß3en, von innen nach außen, wie eine Welle - erst kalt, dann heiß, bis in die letzten Verzweigungen. Ich spürte keinen Kontakt mehr zu all den Zellen, die sich über die Jahre von mir geteilt hatten. Ich fühlte mich allein, und dann ganz, ganz einsam.

Sie erschrickt. Die Gehimströme sind zusammengebrochen, nur noch die vegetativen Funktionen zeigen Aktivität. Der Patient ist bemusstlos. Sie kontrolliert alle Geräte - Sanerstoff, Herzschlag, Blutzucker. Alles normal. Nein, unter soldhen Umständen hat es noch mie eimen Beumsstseinsalfall gegeben. Was ist das? Wie ist das passient? Wenn sie nur miisste, wo sie gerade im Gehim ist. Aber die Zelle, deren Aktivitat sie gerade noch gemessen hat, ist weg, wallscheinlich angestochen, vielleidht zerplatzt.

Sie zicht den Vortrich ganz wenig zurïk. Und damn hat sie eine Ide'e, und probiert ihre letzte Möglidhkeit: Sie hat ja während der ganzen Operation die Aktivitäten anfgezeidunet. Was wïrde passieren, wenn sie das elektrische Aktivitïtsmuster der zerplatzten Zelle iber ihre Elektrode zurïk ins Gehim spiclte? Es sind mur ein parr Klicks auf dem Computer, and ilur Stimulator legt los: Pac. Papapapac. Tmmptrptrtrk. „Hören sie mich?" "Natiorlich höre ich sie! Wie lange brauchen sie denn noch?" Ein Gliik! Der Patient ist wieder wad, bei wollem Beurusstsein! 
Ich fand das sehr eigenartig. Plötzlich war ich wieder eins mit meinen Zellen, das Gefühl war zurück - ach welch eine Wonne - ich war wieder ich, und es schien, als hätte ich all meine Zellen wieder zusammen. Jetzt wollte ich sie nie wieder los lassen, nie wieder.

Und dann spürte ich sie doch wieder, diese Kälte, diese Angst ...

Die zurückgespiclte Aufnahme ist vorbei, der Patient wieder beunsstlos. Die Zelle, an der sie gerade ihre Elcktrode hat, ist wohl wirklich kaputt, aber sic weiß immer noch nicht, was fïr cine Zelle das ist. Sic fïhrt langsam die Elektrode aus dem Gehim heraus, ganz langsam. Für heute ist Schluss, der Patient sollte erst wieder zu sich kommen. Morgen vielleicht? 